Bes, R.E., Reitsma-van Rooijen, M., Curfs, E.C., Jong, J.D. de. Verzekerden positief over invloech van zorgverzekeraar op gezond gedrag. TSG: Tijdschrift voor Gezondheidswetenschappen:

\begin{tabular}{|l|l|}
$\begin{array}{l}\text { Postprint } \\
\text { Version }\end{array}$ & 1.0 \\
\hline Journal website & http://vb23.bsl.nl/frontend/index.asp?custom product id=1388-7491 \\
\cline { 2 - 2 } Pubmed link & \\
\hline DOI &
\end{tabular}

This is a NIVEL certified Post Print, more info at http://www.nivel.eu

\title{
Verzekerden positief over invloed van zorgverzekeraar op gezond gedrag
}

\author{
Romy E. Bes ${ }^{1}$, MARgreet ReITSMA-VAN RoOIJEN ${ }^{1}$, EMILE C. CuRFS ${ }^{2} \&$ Judith D. DE \\ $\mathrm{JONG}^{1}$ \\ ${ }^{1}$ NIVEL (Nederlands instituut voor onderzoek van de gezondheidszorg), Utrecht \\ ${ }^{2}$ Open Universiteit, Heerlen
}

\section{SAMENVATTING}

In de huidige maatschappij neemt de nadruk op preventie en gezonde leefstijl steeds meer toe. Zorgverzekeraars zijn ook steeds meer bezig met het bevorderen van een gezonde leefstijl van hun verzekerden. Maar wat vinden verzekerden hier eigenlijk van? Het NIVEL onderzoek laat zien dat verzekerden positief zijn over het idee dat zorgverzekeraars hun verzekerden stimuleren om gezond gedrag te vertonen. Over een spaarsysteem waarbij punten gespaard kunnen worden door gezond gedrag te vertonen zijn verzekerden niet zo positief. Verzekerden die hun gezondheid als goed ervaren, zijn het meest positief over zo'n spaarsysteem. De meeste verzekerden zijn het er niet mee eens dat mensen die een slechte gezondheid hebben meer moeten betalen voor hun zorgverzekering. Veel verzekerden zijn het er wel mee eens dat mensen die zich ongezond gedragen meer moeten betalen voor hun zorgverzekering. Dit roept een belangrijke ethische discussie op.

\footnotetext{
AbStract

Healthy behaviour, such as exercise and not smoking, is being increasingly emphasized in current society. Health insurance companies are anticipating on this by, for instance, rewarding enrolees who display healthy behaviour such as quitting smoking or joining a gym. But how do enrolees feel about their health insurer trying to influence their behaviour and how do they feel about rewarding enrolees who display healthy behaviour? Results from this NIVEL questionnaire study show that enrolees are quite positive about their health insurer trying to promote healthy behaviour. However, enrolees are not very positive about rewarding enrolees who quit smoking or start exercising. Enrolees who have
} 
Bes, R.E., Reitsma-van Rooijen, M., Curfs, E.C., Jong, J.D. de. Verzekerden positief over invloech van zorgverzekeraar op gezond gedrag. TSG: Tijdschrift voor Gezondheidswetenschappen: 2013, 91(8), 467-470

high self-reported health status are more positive about this rewarding system compared to enrolees with lower self-reported health status. Most enrolees do not agree that enrolees who already have a bad health should pay more for their health insurance. Many enrolees do agree that enrolees who display unhealthy behaviour such as smoking or being overweight should pay more for their health insurance. This raises an important ethical discussion.

In de huidige maatschappij neemt de nadruk op preventie en gezonde leefstijl steeds meer toe. Zorgverzekeraars zijn ook steeds meer bezig met het bevorderen van een gezonde leefstijl van hun verzekerden. Maar wat vinden verzekerden hier eigenlijk van?

\section{NADRUK OP GEZONDE LEEFSTIJL NEEMT TOE}

Het huidige kabinet wil meer in gaan zetten op preventie en een gezonde leefstijl[1]. Dit staat dan ook hoog op de agenda van het ministerie van VWS[2]. Door een gezonde leefstijl, bijvoorbeeld niet roken, gezonde voeding, regelmatige beweging en matig alcoholgebruik, zijn ziekten zoals hart- en vaatziekten, COPD en diabetes voor een groot deel te voorkomen[3]. Hierdoor is veel gezondheidswinst te behalen. Betere leefgewoonten zouden niet alleen de levensverwachting, maar ook het aantal gezonde jaren en het aantal jaren zonder beperkingen of chronische ziekten kunnen vergroten[4].

In de kamerbrief 'Van systemen naar mensen'[2] van het ministerie van VWS staat dat mensen in de eerste plaats zelf verantwoordelijk zijn voor een gezonde leefstijl, maar ook dat bij het bevorderen van een gezonde leefstijl de overheid een rol voor zichzelf en zorgverzekeraars weggelegd ziet. De overheid wil met zorgverzekeraars een convenant sluiten over preventie en het bevorderen van een gezonde leefstijl[2]. Preventie zou voor zorgverzekeraars interessant zijn, omdat het gezondheidswinst kan opleveren voor de verzekerden, wat gemiddeld over een langere periode lagere kosten voor een zorgverzekeraar ten gevolge heeft[5]. Of een gezondere leefstijl daadwerkelijk lagere kosten met zich mee brengt, is echter nog niet bewezen[6].

\section{INVLOED ZORGVERZEKERAARS OP GEZONDE LEEFSTIJL}

Zorgverzekeraars zijn al steeds meer bezig met preventie, zowel in de aanvullende verzekering als buiten de verzekering om[7]. Vanuit de aanvullende verzekering worden verschillende vormen van preventie vergoed zoals een gezondheidstest of gewichtsconsulent. Daarnaast hebben veel zorgverzekeraars bijvoorbeeld een website of magazine met gezondheidsinformatie of sponsoren ze sportieve activiteiten. Ook zijn er zorgverzekeraars die cholesterol verlagende voedingsmiddelen zoals bepaalde soorten margarine vergoeden. Een ander voorbeeld waarbij zorgverzekeraars gezond gedrag willen stimuleren is een zorgpolis waarbij de verzekerde punten kan sparen door gezond te leven. Zo krijgt de verzekerde bijvoorbeeld punten als hij of zij niet rookt en regelmatig beweegt. Met de gespaarde punten kan de verzekerde producten kopen uit de webshop, zoals een kookboek voor 
Bes, R.E., Reitsma-van Rooijen, M., Curfs, E.C., Jong, J.D. de. Verzekerden positief over invloech van zorgverzekeraar op gezond gedrag. TSG: Tijdschrift voor Gezondheidswetenschappen: 2013, 91(8), 467-470

gezonde gerechten, zorgproducten of een wellness arrangement (zie Box 1 voor meer informatie over dit spaarsysteem). Toen dit systeem in 2012 door een zorgverzekeraar werd ingevoerd is dit veelvuldig in het nieuws geweest, omdat het de eerste zorgverzekeraar is die een dergelijk initiatief ontplooit[8]. Er werden vragen gesteld over de uitvoerbaarheid en controleerbaarheid van het systeem. Daarnaast roept het ook een ethische discussie met betrekking tot het onderscheid tussen mensen met een gezonde en ongezonde leefstijl met daaraan gekoppelde financiële consequenties[6;8]. In dit artikel staan twee vragen centraal. De eerste vraag is wat verzekerden er eigenlijk van vinden dat zorgverzekeraars hun verzekerden proberen over te halen tot gezond gedrag. De tweede vraag is hoe verzekerden aankijken tegen dit spaarsysteem.

\section{ONDERZOEK ONDER VERZEKERDEN}

Om deze vragen te beantwoorden heeft het NIVEL in november 2012 een online vragenlijst gestuurd aan alle online leden van het Verzekerdenpanel. 2.242 panelleden hebben de vragenlijst ingevuld (respons van 71\%). Deze leden zijn allen verzekerd bij een van de zorgverzekeraars die vallen onder de Coöperatie VGZ en hebben zelf niet te maken gehad met een spaarsysteem zoals dat hierboven wordt genoemd. Alle percentages die genoemd worden zijn gecorrigeerd voor leeftijd en geslacht, zodat de resultaten wat leeftijd en geslacht betreft representatief zijn voor de algemene bevolking in Nederland.

\section{INVLOED ZORGVERZEKERAAR OP GEZOND GEDRAG GEWAARDEERD}

Aan de verzekerden werd gevraagd of zij het al dan niet goed vinden dat zorgverzekeraars hun verzekerden proberen over te halen tot gezond gedrag. Het blijkt dat zij de invloed van zorgverzekeraars op gezond gedrag waarderen, want een ruime meerderheid (80\%) geeft aan het goed te vinden dat zorgverzekeraars hun verzekerden hiertoe proberen aan te zetten [Figuur 1]. Voorbeelden van toelichtingen die verzekerden hierbij gaven zijn: "Baat het niet, dan schaadt het niet" en "Zowel de zorgverzekeraar als de cliënt profiteren hiervan". Voorbeelden van toelichtingen van verzekerden die het niet goed vinden dat zorgverzekeraars hun verzekerden proberen over te halen tot gezond gedrag, zijn "Het is de eigen verantwoordelijkheid van mensen" en "Geen taak van de zorgverzekeraar". Hoger opgeleiden en verzekerden die een betere ervaren gezondheid hebben staan er vaker achter dat zorgverzekeraars hun verzekerden proberen over te halen tot gezond gedrag.

\section{VERZEKERDEN ZIJN NIET POSITIEF OVER EEN SPAARSYSTEEM}

Aan de verzekerden is ook gevraagd wat zij vinden van een spaarsysteem waarbij verzekerden punten kunnen sparen door gezond gedrag te vertonen. Meer dan de helft van de respondenten (59\%) geeft aan dat ze dit spaarsysteem niet goed vinden (Figuur 1). Voorbeelden van redenen die zij hiervoor noemen zijn "Controle lijkt me moeilijk" en "Een geldelijke korting is meer op zijn plaats" . Ongeveer twee vijfde (41\%) geeft aan het spaarsysteem wel een goed idee te vinden (Figuur 1). 
Bes, R.E., Reitsma-van Rooijen, M., Curfs, E.C., Jong, J.D. de. Verzekerden positief over invloech van zorgverzekeraar op gezond gedrag. TSG: Tijdschrift voor Gezondheidswetenschappen: 2013, 91(8), 467-470

Voorbeelden van redenen die verzekerden hierbij noemen zijn: "Het is een extra stimulans, gezond leven mag beloond worden" en "Het kan een gezonde leefwijze stimuleren".

\section{[FIGUUR 1]}

\section{VERZEKERDEN MET BETERE ERVAREN GEZONDHEID VAKER EENS MET SPAARSYSTEEM} Of verzekerden voor of tegen een spaarsysteem voor gezond gedrag zijn, verschilt niet tussen groepen wat betreft leeftijd en geslacht. Wel zijn verzekerden met een betere ervaren gezondheid vaker voorstander van een spaarsysteem. Wellicht zijn zij meer geïnteresseerd in de producten die met de gespaarde punten gekocht kunnen worden. Het is ook mogelijk dat ze positiever zijn omdat zij denken weinig aan hun gedrag te hoeven veranderen om te kunnen profiteren van de kortingen. Ook zijn verzekerden met een hoog opleidingsniveau vaker voorstander van een spaarsysteem vergeleken met mensen van een midden en laag opleidingsniveau, ook als gecorrigeerd wordt voor ervaren gezondheid. Ervaren gezondheid is echter niet hetzelfde als het al dan niet vertonen van gezond gedrag. Het is bekend dat mensen met een lage sociaal economische status vaker ongezond gedrag vertonen, zoals roken of niet sporten[9]. Mogelijk is het zo dat mensen met een lagere opleiding vaker tegen een spaarsysteem zijn, omdat zij vaker hun gedrag zullen moeten veranderen om punten te sparen.

\section{SOLIDARITEIT}

Als verzekeraars hun verzekerden overhalen om gezond gedrag te vertonen, kan dit betekenen dat gezonde verzekerden het idee hebben dat ze moeten betalen voor de negatieve gevolgen van ongezond gedrag door andere verzekerden. Het kan ook zo zijn dat als verzekeraars gezond gedrag belonen door kortingen te geven, mensen die ongezond gedrag vertonen het idee hebben dat zij hierdoor kortingen mis lopen en dus meer moeten betalen. Dit zou dan ingaan tegen het principe van solidariteit waarbij iedereen evenveel betaalt (gedifferentieerd naar draagkracht, niet naar persoonskenmerken), zodat iedereen benodigde zorg kan krijgen. Wat vinden verzekerden? Zouden mensen die ongezond gedrag vertonen meer moeten betalen voor hun zorgverzekering? En zouden mensen die veel zorg gebruiken omdat ze een slechtere gezondheid hebben (bijvoorbeeld chronisch zieken) meer moeten betalen voor hun zorgverzekering? Iets meer dan de helft (52\%) is het er (deels-helemaal) mee eens dat mensen die ongezond gedrag vertonen meer zouden moeten betalen voor hun zorgverzekering. 36\% is het hier (deels-helemaal) mee oneens.

Tegenstanders van een spaarsysteem zijn het vaker (deels-helemaal) oneens met de stelling dat mensen die ongezond gedrag vertonen meer zouden moeten betalen voor hun zorgverzekering, dan voorstanders van een spaarsysteem, respectievelijk $46 \%$ en $21 \%$. Wanneer aan verzekerden werd gevraagd of mensen die veel zorg gebruiken omdat ze een slechtere gezondheid hebben, bijvoorbeeld mensen met een chronische ziekte, meer zouden moeten betalen voor hun zorgverzekering was $86 \%$ het hier (deels-helemaal) mee oneens. Dit wijst erop dat verzekerden meer solidair zijn wanneer mensen al ziek zijn, dan wanneer mensen gedrag vertonen waardoor ze meer kans hebben op ziekte. Dit is ook in ander onderzoek gevonden[10]. Of mensen solidair zijn, wordt onder andere bepaald door of mensen vinden dat anderen hulp 
Bes, R.E., Reitsma-van Rooijen, M., Curfs, E.C., Jong, J.D. de. Verzekerden positief over invloech van zorgverzekeraar op gezond gedrag. TSG: Tijdschrift voor Gezondheidswetenschappen: 2013, 91(8), 467-470

verdienen. Twee van de vijf criteria om te bepalen of mensen hulp verdienen zijn volgens van Oorschot 'onmacht' en 'behoeftigheid'[11-13]. Mensen die chronisch ziek zijn hebben vaak niet de macht om zelf wat aan hun situatie te doen en hebben behoefte aan hulp in tegenstelling tot mensen die ongezond gedrag vertonen. Daarom zijn mensen meer solidair met zieke mensen dan met mensen die ongezond gedrag vertonen.

\section{TOT SLOT}

Veel verzekerden vinden het goed als zorgverzekeraars hun verzekerden stimuleren tot gezond gedrag. Zorgverzekeraars zijn hier ook steeds meer mee bezig op verschillende manieren. Ons onderzoek laat zien dat mensen een spaarsysteem niet zo'n goed idee vinden. Daarnaast blijkt uit dit onderzoek dat een initiatief als dit spaarsysteem juist mensen aantrekt die al gezonder zijn. De vraag is dan ook of het spaarsysteem wel preventief werkt of dat het de zorgverzekeraar alleen een beter imago oplevert. Het Centrum voor Ethiek en Gezondheid schrijft in de signalering Leefstijl differentiatie in de zorgverzekering dat er nog geen bewijs is dat het belonen van gezond gedrag of afstraffen van ongezond gedrag door financiële prikkels in de zorgverzekering zal werken, onder andere omdat het moment dat je gezond gedrag vertoont en het moment dat je daarvoor beloont wordt te ver uit elkaar liggen[14]. Daarnaast roept het ook ethische vragen op als er onderscheid wordt gemaakt tussen mensen met een gezonde en mensen met een ongezonde leefstijl, waarbij mensen met een ongezonde leefstijl moeten opdraaien voor de kosten die een ongezonde leefstijl met zich meebrengt en waarbij mensen die een gezonde leefstijl hebben hiervoor beloond worden. Is het onderscheiden van deze groepen überhaupt mogelijk? En is dat niet stigmatiserend en een inbreuk op de privacy? Voorlopig zal het debat over de invloed van de zorgverzekeraar op gezond gedrag nog niet ophouden.

\section{[Box 1]}

\section{LITERATUURLIJST}

1. Bruggen slaan. Regeerakkoord VVD - PvdA. Den Haag: 2012.

2. Ministerie van VWS. Kamerbrief gezamenlijke agenda van VWS 'Van systemen naar mensen'. Den Haag: Kenmerk: MEVA/AEB-3155166; 2013.

3. Rijkschroeff-van der Meer ACJ. Welvaartsziekten: andere ziekten, andere aanpak. Den Haag, Nederland: Raad voor Volksgezondheid en Zorg [RVZ]; 2011.

4. Raad voor Volksgezondheid en Zorg. Preventie van welvaartsziekten. Effectief en efficiënt georganiseerd. Den Haag: 2011.

5. Koopmans B, Korevaar J, Nielen M, Verhaak $P$, Jong J de, Dijk L van, Noordman J, Veenhof $C$, Schellevis F. Overzichtstudies. Preventie kan effectiever! Deelnamebeleid en deelnametrouw aan preventieprogramma's in de zorg. NIVEL, Utrecht: 2012.

6. Centrum voor Ethiek en Gezondheid. Leefstijldifferentiatie in de zorgverzekering. Een overzicht van ethische argumenten. 2013.

7. Nationaal Kompas Volksgezondheid. Url: http://www.nationaalkompas.nl/preventie/thema-s/zorgverzekeraars/preventie-buiten-deverzekering/. 28-3-2013. 
Bes, R.E., Reitsma-van Rooijen, M., Curfs, E.C., Jong, J.D. de. Verzekerden positief over invloech van zorgverzekeraar op gezond gedrag. TSG: Tijdschrift voor Gezondheidswetenschappen:

2013, 91(8), 467-470

8. RTL. Nieuw: Bonuspunten voor gezonde leefstijl. Url:

http://www.rtl.nl/components/actueel/editienl/nieuws/2012/w38/verzekeraar-geeft-

bonuspunten-voor-gezond-leven.xml. 7-9-2012.

9. Jansen J, Schuit AJ, Lucht F van der. Tijd voor gezond gedrag. Bevordering van gezond gedrag bij specifieke groepen. Bilthoven: Rijks Instituut voor Volksgezondheid en Milieu (RIVM); 2002.

10. Kloosterman R. Solidariteit in de gezondheidszorg. Centraal Bureau voor de Statistiek; 2011.

11. Oorschot $W$ van. Who should get what, and why? On deservingness criteria and the conditionality of solidarity among the public. Policy and Politics 2000; 28(1):33-49.

12. Oorschot $W$ van, Kalmijn $M$. Van je familie moet je het hebben... Familiesolidariteit in Brabant in vergelijkend perspectief. Departement sociaal-culturele wetenschappen, Universiteit van Tilburg; 2005.

13. Oorschot $W$ van. Making the difference in social Europe: deservingness perceptions among citizens of European welfare states. Journal of European Social Policy 2006; 16(1):23-42.

14. Achmea. Geen overeenkomst tussen Achmea en Slotervaartziekenhuis voor 2013. Url: https://www.achmea.nl/pers/paginas/geen-overeenkomst-tussen-achmea-enslotervaartziekenhuis-voor-2013.aspx. 31-1-2013.

15. Menzis. Url:

http://www.menzis.nl/web/Consumenten/Klantenservice/SpaarprogrammaSamenGezond/ WatlsSamenGezond.htm. 4-3-2013. 
Bes, R.E., Reitsma-van Rooijen, M., Curfs, E.C., Jong, J.D. de. Verzekerden positief over invlooeh van zorgverzekeraar op gezond gedrag. TSG: Tijdschrift voor Gezondheidswetenschappen: 2013, 91(8), 467-470

\section{BOX EN FIGUUR}

\section{Box 1: uitleg spaarsysteem}

Het spaarsysteem dat ontwikkeld is door deze zorgverzekeraar is bedoeld om mensen te stimuleren gezond gedrag te vertonen. Verzekerden kunnen bijvoorbeeld punten sparen door niet te roken en regelmatig te bewegen. Daarnaast kun je ook punten sparen als je bloeddonor bent of mantelzorger. Deze zaken worden niet gecontroleerd, het systeem is gebaseerd op vertrouwen. Met de gespaarde punten kunnen de verzekerden producten kopen uit de webshop van de zorgverzekeraar, zoals een kookboek voor gezonde gerechten, zorgproducten of een wellness arrangement. De zorgverzekeraar is ook van plan om het mogelijk te maken om met de punten te sparen voor de afbetaling van het eigen risico[15].

Figuur 1: Percentages voor- en tegenstanders van de invloed van de zorgverzekeraar om gezond gedrag te bevorderen en percentages voor- en tegenstanders van een spaarsysteem.

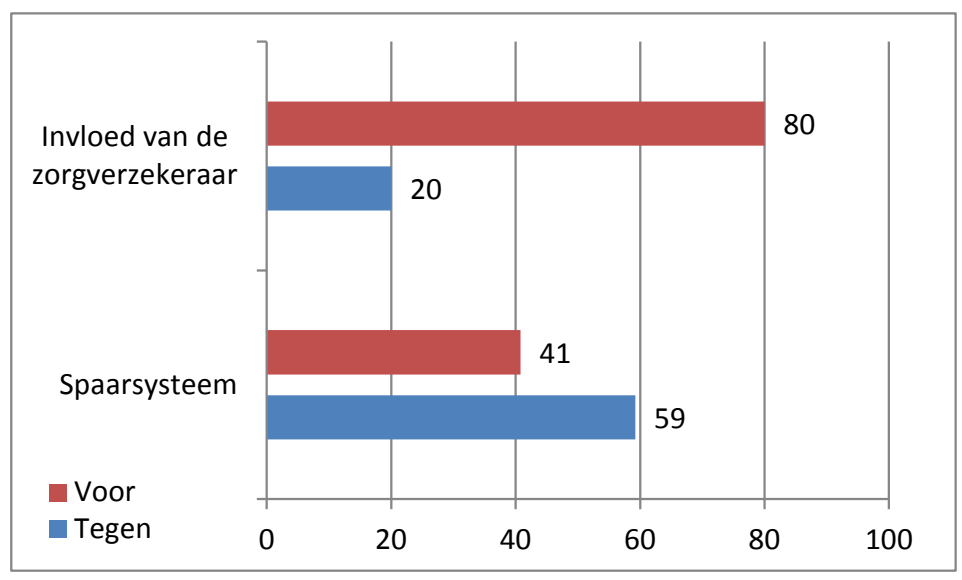

